\title{
The Individual and the Organizational Model of Quantum Decision-Making and Learning (MQDM\&L): An Introduction and the application of the Quadruple Loop Learning
}

Meir Russ

\section{Professor Emeritus}

Austin E. Cofrin School of Business, University of Wisconsin-Green Bay,

Green Bay, WI 54311, USA

russm@uwgb.edu or meir.russ@gmail.com

\begin{abstract}
The new Post Accelerating Data and Knowledge Online Society, or 'Padkos' requires a new model of decision making. This introductory paper proposes a model where decision making and learning are a single symbiotic process, incorporating man and machine, as well as the AADD (ánthrōpos, apparatus, decider, doctrina) diamond model of individual and organizational decision-making and learning processes. The learning is incorporated by using a newly proposed quadruple loop learning model. This model allows for controlled changes of identity, the process of creating and the sense making of new mental models and assumption, and reflections. The model also incorporates the recently proposed model of quantum decision-making, where time collapse of the opted past and the anticipated future (explicitly including its time horizon) into the present play a key role in the process, leveraging decision-making and learning by human as well as Artificial Intelligence (AI) and Machine Learning (ML) algorithms. The paper closes with conclusions.
\end{abstract}

Key words: Model of Quantum Decision-Making and Learning (MQDM\&L), AADD diamond model, organizational, individual, decision-making, learning, quadruple loop learning, Padkos

1. Introduction

A number of insights from emerging trends, which build on new scientific and technological developments suggest that a new model of decision-making (DM) and learning might be needed, specifically: 1. Discontinuous change-continuous technological revolutions; 2. Artificial Intelligence (AI)-Machine Learning (ML)-Big data; and 3. Neuroscience. These three developments and their impact on decision-making and learning (DM\&L) are discussed below.

Both individuals and organizations are today faced with a discontinuous change of titanic scope and magnitudes, the continuously accelerating technological revolution (see Padkos at Russ, 2021) requiring increasingly faster responses in a new, uncertain, ambiguous and/or unknowable context, and continuous, lifelong learning, necessitating the amalgamation of decision-making (DM) and the learning processes into one, single, symbiotic, and synchronized process. This context is forcing the decision-maker/learner into making decisions that are new, and not 
necessarily supported or directly related by/to the past or their past decision. The actor/entity can less and less trust their intuition (system 1, fast thinking, in Kahneman, 2011) or their traditional heuristics which forces them into a slow thinking mode (System 2 in Kahneman, 2011) while thinking itself is being pushed to a faster and faster pace, and as such will have to be supported by big data and by ML (or actually conducted by ML).

The nature of the Decision-Making and Learning (DM\&L) process in organizations is also changing due to the infiltration of AI/ML into the DM\&L process. Some even suggest that AI driven decision-making algorithms might be at the core of the digital operating model of the firm of the future that will revolutionize the landscape of business in the 21 st century. This results from an automation of decision-making (replacing humans) while increasing the rate of return on scale, scope, and investment in learning (Iansiti and Lakhani, 2020, p. 53). Notwithstanding, it can be assumed that more and more decisions will be taken by the AI algorithms and platforms and supported by big data (Araujo et al., 2020; Jarrahi, 2018), both horizontally and vertically (context specific, see example at Vaishya et al., 2020; and a review at Shahid, Rappon \& Berta, 2019).

The harnessing of big data by deep and machine learning (supported by data science, e.g., Elshawi et al., 2018) is creating a new context for DM\&L, since in many cases it is the ML (or Deep Learning) + big data that makes the decision (or a recommendation), both for the individual and for the organization. For example, "Smart" homes, cars, and workspace will become a reality in the very near future for more and more individuals, while "Smart" manufacturing and office-space (collaboration of robots and people) are already a reality for manufacturing or service companies or those that have a supplier or buyer relationship with a "Smart" supplier or customer (see example at Trakadas et al., 2020). This is another factor to consider when discussing individual and/or organizational DM\&L processes.

Moreover, more is known today based on studies in neuroscience about decisions and learning of individuals than ever before, and as elsewhere, such knowledge is accumulating at an exponential rate. For example, it was documented that our brains make decisions a few (approximately 7) seconds before our conscious mind recognizes that as "we made a decision" (Soon et al., 2008 and review for example in Haggard, 2019). Also, researchers proved that memories can be erased (Ecker, 2018), and false memories can be created (de Lavilléon et al., 2015).

Human body-machine interface studies (including neural rehabilitation, see Casadio et al., 2012) and prosthetic limb control (see e.g., Wood, 2014) studies were followed by proposals for braincomputer interfaces (Lance et al., 2012) that were recently implemented (Kapur et al., 2020). Moreover, human brain/cloud interface is anticipated to be used by futuristic technologies, referred to "neuralnanorobotics" (Martins et al., 2019), as well as early research of direct brain to brain communication is currently being conducted (Jiang et al. 2019). This all points to a changing context for, and new understanding of human decision-making processes. 
Moreover, neuromarketing is another fruitful area of research with a heavy focus on customer decision-making (see for example reviews in Fortunato et al., 2014; Nilashi et al., 2020), also causing major ethical concerns (see more about ethics below).

There are additional aspects that would indicate that this point in history of Homo Sapiens is a unique inflection point. For example, human activity driven climate change (e.g., McMichael et al., 2006) which causes global warning and making significant parts of the planet uninhabitable and potentially causing flooding of major urban areas around the world (e.g., Xue et al., 2017). Or, being the first generation of a multi-planetary species (Musk, 2017), and the first generation to consider the possibility of viewing death as a curable disease (Istvan, 2019). For the needs of this paper the three listed above will suffice and there is no need to elaborate on the additional factors listed here or others, at this point.

This introductory paper has three novel contributions. First, the paper details the nature of the symbiotic relationship between decision-making and learning as one amalgamated process and introduces the AADD (ánthrōpos, apparatus, decider, doctrina) diamond model of individual and organizational decision-making and learning process. Next, the paper introduces the quadrupled feedback loop learning model, one that allows an entity to control its identity. Finally, the paper details the combined Model of organizational and individual Quantum Decision-Making and Learning (MQDM\&L).

The remainder of the paper is organized into the following sections. In Section 2 the paper briefly discusses the subject of decision-making. Section 3 introduces the AADD (ánthrōpos, apparatus, decider, doctrina) amalgamated diamond model of decision-making and learning. Section 4 elaborates on the quantum metaphor to discuss the collapse of past and future time frames into the present and details the combined quantum decision-making and learning model. Section 5 introduces the novel quadruple loop feedback model. In Section 6 the paper adds the ethical and the cybersecurity considerations into the model. Finally, the paper closes with brief conclusions in Section 7.

\section{Decision-making (DM)}

The academic literature regarding DM, both at the individual and org/team unit of analysis is farreaching (and beyond the scope of this paper). The literature covers theories of individual DM as framing and reference dependence, behavioral economics, bounded rationality and decision heuristics, among others (see examples and reviews from diverse perspectives in Daft, 2014; Lau, 2003; Milner \& Rosenstreich, 2013; Wilson \& Dowlatabadi, 2007). Organizational models of DM include, but are not limited to, rational, administrative, political, stage based (see interesting review at Langley et al., 1995), sense making and decisions in public organizations, (Nutt \& Wilson, 2010), ad hoc problem solving, exception management (Luoma, 2016), and the garbage can model of decision making (Cohen, March, \& Olsen, 1972). The brief discussion above about the impact that big data and ML has (and will have) on DM\&L, is espousing the preference given in this model of DM\&L, by the author, to the garbage can model of DM (Cohen, March, \& Olsen, 1972), since it overtly and seamlessly enables the incorporation of data and digital algorithms into the model described here. 
3. The AADD (ánthrōpos, apparatus, decider, doctrina) diamond model

Russ (2021) recently described a model whereby the decision-making and the learning processes must occur simultaneously due to the external pressures and demands (see also Choo, 2002) and such a seamless process is enabled by the AI machine algorithms (ML, Deep Learning, etc.) and digital systems infrastructure supported by big data and cloud computing (e.g., Hashem et al., 2015). For example, see the McKinsey \& Company report on the transformation in healthcare resulting from the utilization of $\mathrm{AI}$, and the impact it will have on organizations and their workforce (Spatharou, Hieronimus \& Jenkins, 2020).

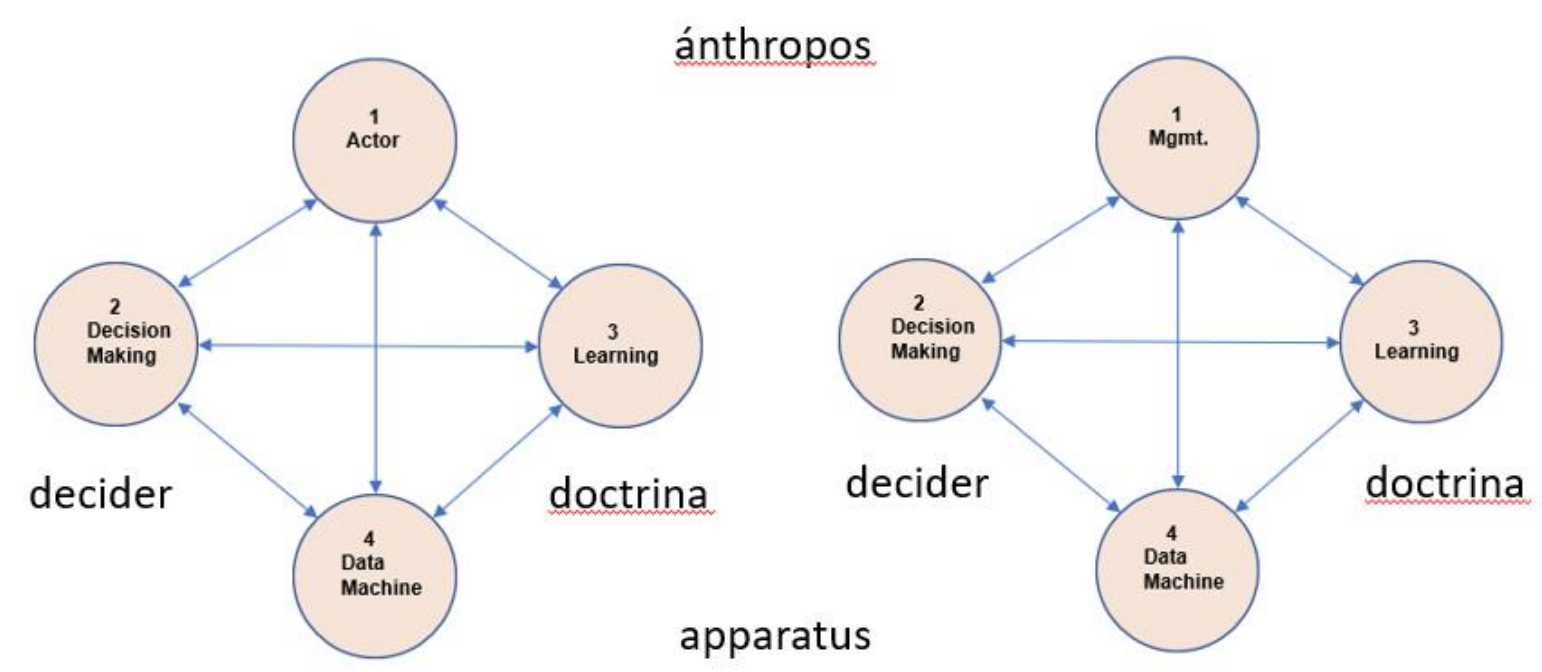

Figure 1. The AADD diamond model of Individual and organizational decision-making and learning process

Source: Author's elaboration.

Moreover, the most recent research suggests that data driven DM utilizing analytics allows companies to outperform their competition significantly (Gottieb \& Weinberg, 2019).

Incorporating blockchain technology into this mix will only accelerate and increase the prospects of such technologies to transform business and industries (Akter et al., 2020) as they try to match the needs and challenges resulting from the continuously accelerating technological revolution, (Russ, 2021).

All this and more requires and enables a new DM\&L process (see Figure 1 for the basic diamond description). The model described below is an attempt to do just that in more detail.

4. The quantum metaphor and maybe more

Gleaning from quantum physics (e.g., Briggs et al., 2013), the collapse of the wave function when being monitored by an observer is mostly known through the thought experiment of Schrödinger's cat and the famous question: is the cat alive or dead, and when (see recent 
discussion in Merali, 2020). As suggested by Josephson, (2002), in a biological reality sense, it is the decision made by the observer to observe that is causing the collapse of the wave (see Table 1, p. 44). Here, the author will use such a collapse as a metaphor in terms of a time frame collapse (and not probabilities). There might be more than a metaphor here since, based on neural brain studies, there is evidence that memorizing the past is (in some cases) rewriting the memory from 'a new' (see Paul, 2012) and that the expectations (about the future) of an observer have an impact on the neural level of their perceptions of reality (see Dolan, 2021). For an observer, at a specific point in time (and space) there is only the present; future and past are the product of their mind (see discussion in Fernandez, 2019).

In this paper the author will elaborate on the model proposed in Russ, $(2018,2021)$ of quantum decision-making (the organizational/team and the individual) and will also utilize the combination of DM and learning into one process (as mentioned above) while adding a quadruple feedback loop learning model to complete this model, (see Figures 2 and 3).

For the organizational process, the alignment of the time horizon as well as the political process of which a specific (out of the four) feedback loop to adopt are probably the most contagious stages. If the data needed for the use of AI/ML algorithm is available, this could make such a process more efficient, but not necessarily effective, since those algorithms do not seem to be trained yet in utilizing the double, triple or quadruple loops. This is not to say that the algorithm questions or inputs cannot cause a human actor to engage in a double loop learning (D. M. Worden, personal communication, March 21, 2021) or even in a higher-level refinement. On a more basic level, having the needed data at the appropriate form for such algorithms and/or for a human decision-maker is far from simplistic. A recent case of the pandemic data (or lack off) can vividly illustrate such complexity (see the case described in Meyer and Madrigal, 2021).

For the individual, the choice of which feedback loop to pursue will be theoretically easier but getting to use the triple or the quadruple loop may cause emotional difficulties. Also, access to data might not be simple in many cases. Some new technologies might help here, for example using virtual reality for human-computer interaction (Alonso-Valerdi et al., 2017) to support gaming and/or scenario planning can be useful in experimenting with new possibilities and enable the individual to experiment with different identities, and issues and solutions. Additional stages of validation and confirmation are of course advisable as well as a follow up.

As suggested in Russ (2018, 2021), it is the collapse of a specific future (including a specific time horizon) and a particular past, at a specific point in time that is enabling the decision to happen (see also the discussion of time by Myllykoski, 2017). This is different from other models of quantum DM that looks at the probabilistic aspects of DM (e.g., Yukalov \& Sornette, 2016). To the best of our knowledge this is the first such model suggesting the collapse of time frames in managerial literature. 


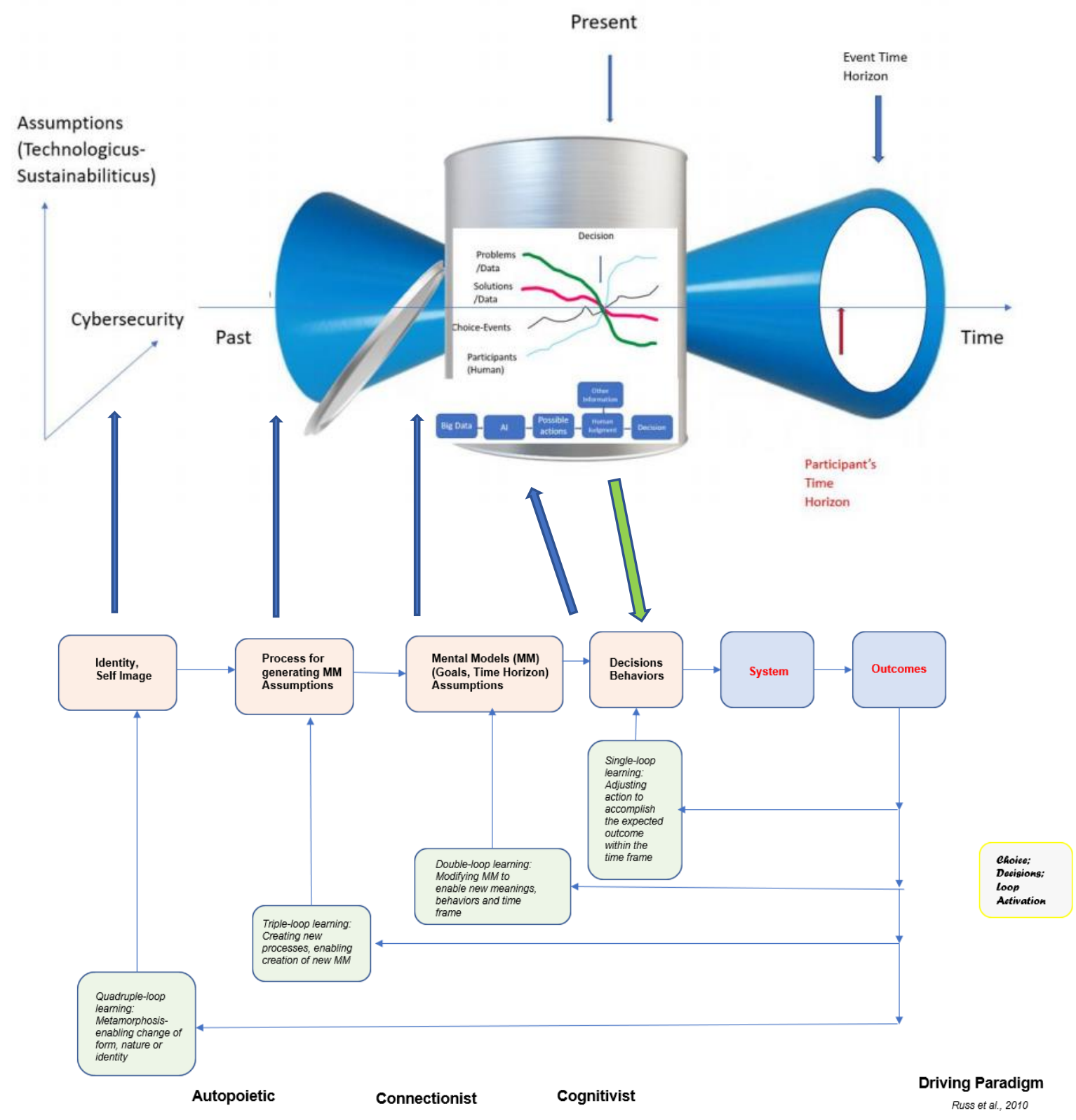

Figure 2. Organizational Model of Quantum Decision-Making and Learning (MQDM\&L) Source: Russ 2021, Figure 6b (p. 15) and Author's elaboration.

The model (among many other aspects) can explain why change is so difficult, and also, how change can be accelerated by bringing in a different past, or a different aspect of the past into the collapse of time to accommodate the desired future. This model is consistent with the autopoietic paradigm (see Russ et al., 2010 elaboration on knowledge and learning) and the Luhmann's theory of autopoietic social systems (see discussion at Seidl, 2004). 


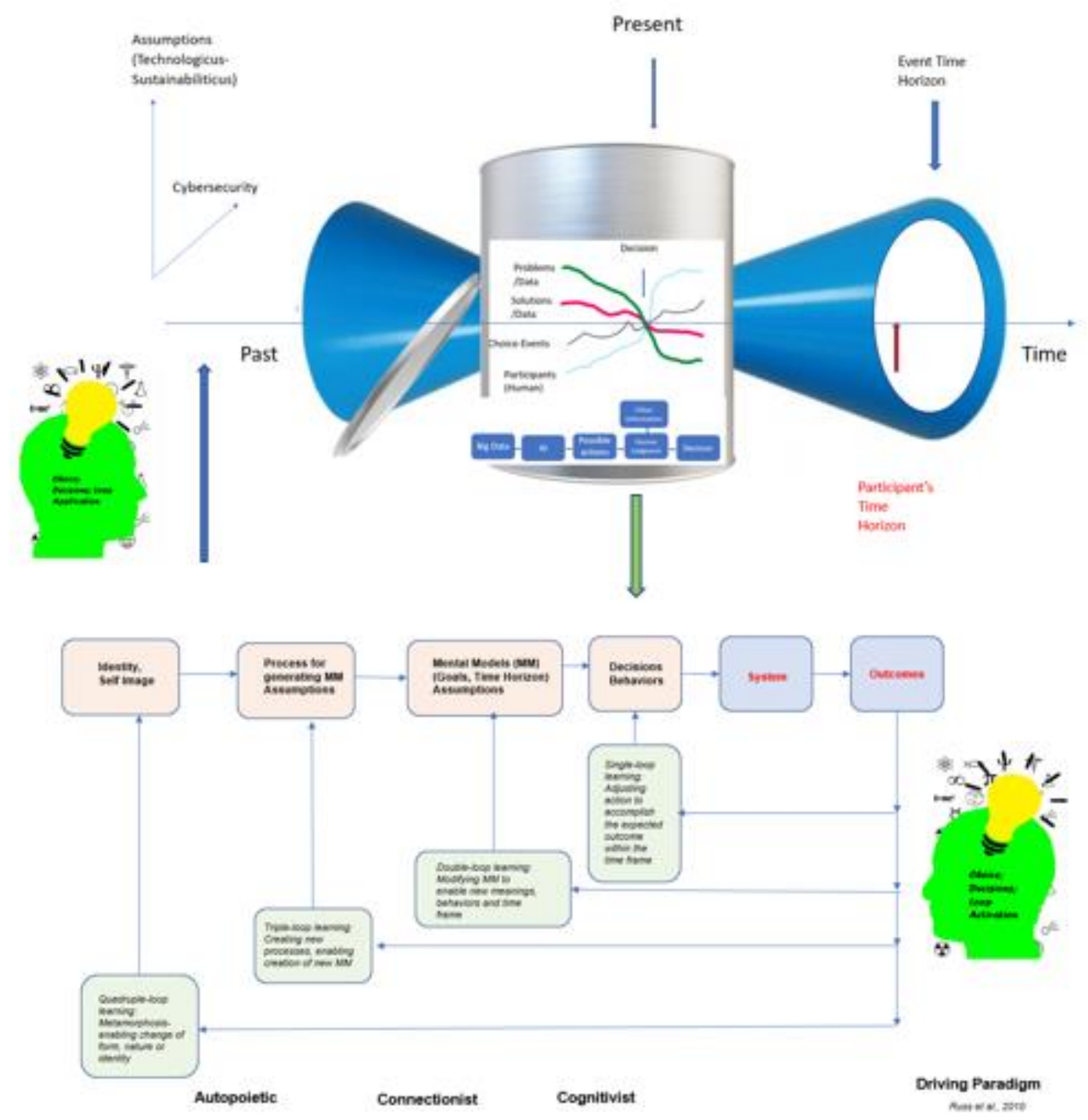

Figure 3. Individual Model of Quantum Decision-Making and Learning (MQDM\&L) Source: Russ 2021, Figure 6b (p. 15) and Author's elaboration.

The actor (or entity) has a choice which past to bring forward (consistent with neural studies, as mentioned earlier) and consciously and rationally activating different modes of the feedback (or using different mechanisms, see example at Kross, 2021) may arrive to a different decision. The same can be said about the future that is brought back to the present. For example, using 'presencing' (and the U theory, see Scharmer, 2009) may enable a completely new set of potential futures, and result in a different decision. 
Such a collapse (choice event in terms used by the garbage can model of decision-making, Cohen et al., 1972) is critical in framing the issue at hand and the relevant solutions. Framing is known to be a major issue in making decisions; one of many cognitive and unconscious biases which could result in non-optimal decisions (see examples in Baker \& Nofsinger, 2002; and Chira et al., 2008). The minimizing effects of such biases will be another reason why incorporating ML and algorithms both on the learning end and on the decision-making end can improve the DM\&L process. Moreover, incorporating machine learning and the contribution of AI to the DM\&L processes may be required since such technologies may force the actor to make a decision or 'deal' with a decision/learning conducted by the AI in a situation that is NOT their choice, but is driven by the algorithm, which is forcing the timing of the choice event and the set of issues and solutions. As such, the model of DM\&L used here, must accommodate human based DM, Machine autonomous DM and a mixed DM (see a simplistic model in Colson, 2019).

Moreover, forgetting (or reframing) can also enable a complete new set of definitions of an issue and of alternative solutions. This might be needed today more frequently than ever, for example due to the shrinkage of half-life of knowledge (Russ, 2021).

\section{The learning feedback loops-the quadruple loop learning model}

The need (or an opportunity) to frame, or reframe (an issue, solution, and/or an identity) is where the quadruple feedback loops are vital because they provide the flexibility, if so chosen by the actor, to decide which feedback loop to use for the purpose of framing issues and solutions, and possibly enable a new learning cycle, in some cases, even for a particular purpose.

The first feedback loop is the traditional/standard feedback used for the purpose of adjusting actions to accomplish the expected/planned outcome within the planned time frame. Such a feedback is not necessarily simple, as the discussion regarding "System Thinking" in the Fifth Discipline (Senge, 2006) illustrates, since the feedback can be positive or negative, with or without time lags, simple or complex (see also the Balanced Scorecard by Kaplan and Norton, 1996); and can be used as feedback, concurrent and feedforward control (Crossan et al., 1999).

Double loop learning was originally proposed by Argyris, (1977) and insinuated that the purpose of the feedback might require change in goals, time horizon, and assumptions, by developing new mental models and the creation of new meaning (e.g., Greenwood, 1998). The typical simplistic example of such learning in the business context is the switch from market share as a goal to profitability (or visa-versa), since giving up on one, makes the other one easier to achieve.

Triple loop learning is defined as the creation of a new process, which could enable the creation of new mental models (see examples at Leifer \& Steinert, 2011; McClory et al., 2017; Peschl, 2007; and Yuthas et al., 2004). Crossan et al., (1999) proposed four processes to support such organizational learning: Intuiting, Interpreting, Integrating and Institutionalizing; at three levels: the individual, groups/teams and the whole organization, enabling organizational strategic renewal. 
The quadruple loop learning proposed here is enabling the all-embracing change of ones' (actor and/or entity) identity; a metamorphosis (not renewal) of an organizational (or individual) identity; a complete change in form. For an organizational example, consider the case of the evolution of Starbucks from a small coffee chain in Seattle to the 'third place' (White, 2004) or the evolution of Google from a search engine into Alphabet Inc. (Lee, 2019). For an individual case, consider the case of a young entrepreneur that can morph into a serial entrepreneur (Wright et al., 1997) versus an entrepreneur who can grow a firm from a two-man garage into a global success (e.g., Steve Jobs - Gallo, 2011). The process described here is significantly different from the one (using the same name) described by Lee et al., (2020) which identifies a different process between backstage and front stage for a public entity, but, is not encompassing the allembracing change of the identity of the public organization.

The possibilities described here, and the range of choices (which one of the four choices/mindset will be dominant) enables an entity (an individual or an organization) to identify a variety of gaps and needs to acquire new knowledge or learn a new skill/capability. Here, the process described by Crossan et al., (1999) or the models of learning as described in Russ (2021) can be useful.

\section{Ethics and Cybersecurity}

Included in Russ (2021) framework for KM that solidifies DM\&L as one process, are the concerns regarding ethics and cybersecurity. Obviously, such a discussion is relevant to the specific model of QMDM\&L discussed here.

With such an emphasis on the importance of AI algorithms and the importance of big data, it is only natural that the models of ethical dilemmas/dimensions that incorporate Homo Technologicus and Homo Sustainabiliticus be incorporated here. Their recently updated definitions are cited below:

"Homo-Technologicus_-"a symbiotic creature in which biology and technology intimately interact", so that what results is "not simply "homo sapiens plus technology', but rather homo sapiens transformed by 'technology' into 'a new evolutionary unit, undergoing a new kind of evolution in a new environment"" (Longo, 2002, p. 23), driven by cost efficiencies and instrumental effectiveness within the techno-economic, universal and ontocentric perspectives and expecting adaptation of the "homo sapiens' to the technology."

"Homo sustainabiliticus - a symbiotic being in which biology, technology and morality intimately interact driven by optimization and the balance of costs of the technology solution, while modifying it to optimize the user's adaptation, especially regarding her abilities and the social acceptance recognizing cultural and symbolic differences and environmental responsibilities based on biocentric ethics and the socio-philosophical point of view within her cultural, social, physical, logistic and legal context and cognizant of the ethical dilemmas of adapting the technology to her needs, specifically at the design stage.” $\quad$ Russ, 2021, p. 19 


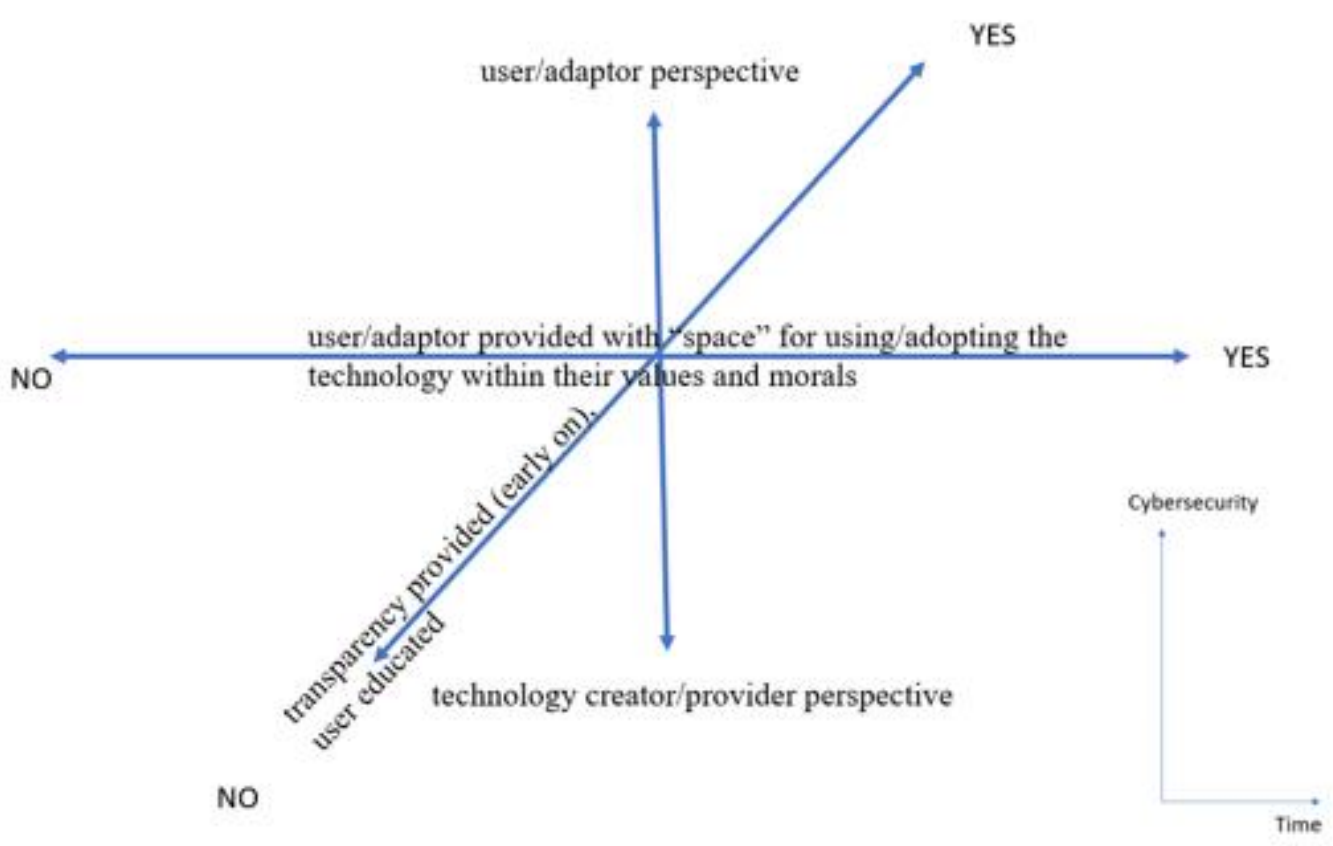

Figure 4. Three practical aspects of Homo Technologicus versus Homo Sustainabiliticus Source: Russ, 2021, Figure 7, p. 20.

The specific concerns (dimensions) listed in Russ (2021, p. 20) regarding ethics, which are also relevant to this model are: 1) Are potential implications of the DM\&L considering the outcomes from the user/object perspective (the effectiveness aspect) taken into consideration? 2) Is the user/object provided with the "space" for "using/adopting the technology within their values and morals", in the autopoietic meaning of self-organizing, in "her context"? 3) Is the user knowledgeable sufficiently to make educated choices about the potential tradeoffs resulting from the specific outcomes and have the legal rights to do so? Figure 4 (above) delineates the space of the dilemmas as mentioned here. From a software development perspective, the evaluative framework proposed by Rieger and Majcherzak (2019) points to how the ethical considerations described in Homo Sustainabiliticus might be weighted for inclusion in digital algorithms. On the other hand, Greene, Hoffmann and Stark (2019) seem to approach some of the same dilemmas from a modified Homo-Technologicus perspective and identified seven core ethical themes and two major areas of failure (which also can serve as opportunities for improvement). Regardless, ethical consideration must be a part of any DM\&L model.

Another implication of the ample reliance of the QMDM\&L on AI and big data is the need to consider cybersecurity as an integral aspect of the model. The framework for cyber security that was proposed in Russ (2021), is suggested to be used in this model as well (see Figure 5 below). 


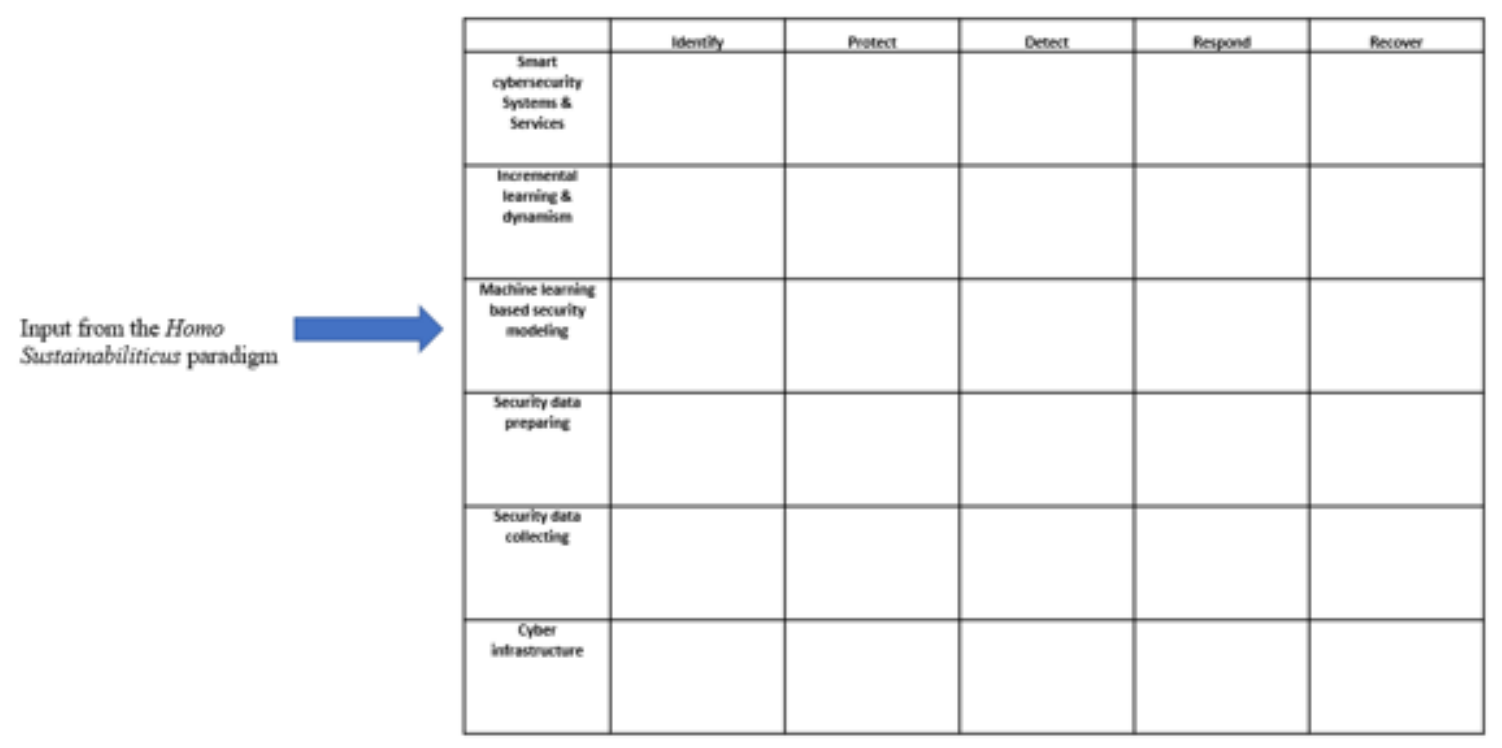

Figure 5. Cyber Security. Source: Russ, 2021, Figure 8, p. 21

\section{Conclusions}

The combined model of the quantum decision-making, suggesting the collapse of the past and the future at the present time when the decision is taken, while explicitly defining the time horizon of the future under consideration and the quadruple feedback loop learning process could open new avenues both for AI/ML algorithms learning (improving on the efficiency of the process) as well as avenues to improve on the effectiveness of organizational decision-making from the leadership/top management perspective. This new model also opens many new research avenues for academics both from the managerial perspective as well as from data and computer science perspectives.

Acknowledgments: The author is grateful to Chayale Szarfer for her help with the graphics, and to Daniel Worden for his helpful feedback and comments.

\section{$\underline{\text { References }}$}

Akter, S., Michael, K., Uddin, M. R., McCarthy, G., \& Rahman, M. (2020). Transforming business using digital innovations: The application of AI, blockchain, cloud and data analytics. Annals of Operations Research, 1-33. Available at https://scholars.uow.edu.au/display/publication142615

Alonso-Valerdi, L. M., Luz María, A. V., Mercado-García, V. R., \& Víctor Rodrigo, M. G. (2017). Enrichment of human-computer interaction in brain-computer interfaces via virtual environments. Computational Intelligence and Neuroscience, 6076913. https://doi.org/10.1155/2017/6076913

Araujo, T., Helberger, N., Kruikemeier, S., \& De Vreese, C. H. (2020). In AI we trust? Perceptions about automated decision-making by artificial intelligence. AI \& SOCIETY, 35(3), 611-623.

Argyris, C. (1977). Double loop learning in organizations. Harvard Business Review, 55(5), 115-125. 
Baker, H. K., \& Nofsinger, J. R. (2002). Psychological biases of investors. Financial Services Review, 11(2), 97116.

Briggs, G. A. D., Butterfield, J. N., \& Zeilinger, A. (2013). The Oxford questions on the foundations of quantum physics. Proceedings of the Royal Society A: Mathematical, Physical and Engineering Sciences, 469(2157), 20130299.

Casadio, M., Ranganathan, R., \& Mussa-Ivaldi, F. A. (2012). The body-machine interface: A new perspective on an old theme. Journal of Motor Behavior, 44(6), 419-433. https://doi.org/10.1080/00222895.2012.700968

Chira, I., Adams, M., \& Thornton, B. (2008). Behavioral bias within the decision making process. Journal of Business \& Economics Research, 6(8), 11-20.

Choo, C. W. (2002) Sensemaking, knowledge creation, and decision making. In C.W. Choo and N. Bontis (Eds.) The Strategic Management of Intellectual Capital and Organizational Knowledge. New York: Oxford University Press, pp. 79-88.

Cohen, M. D., March, J. G., \& Olsen, J. P. (1972). A garbage can model of organizational choice. Administrative Science Quarterly, 17(1), 1-25.

Colson, E. (2019). What AI-driven decision making looks like. HBR.org. Available online: https://hbr.org/2019/07/what-ai-driven-decision-making-looks-like

Crossan, M. M., Lane, H. W., \& White, R. E. (1999). An organizational learning framework: From intuition to institution. Academy of Management Review, 24(3), 522-537.

Daft, R. (2014). Management, 11th ed.; Cengage Learning: South-Western, UK.

Dolan, E. W. (March 14, 2021). Neural representations of reality are altered by expectations. Psypost.org. Available at https://www.psypost.org/2021/03/neural-representations-of-reality-are-altered-by-expectations-60051

Ecker, B. (2018). Clinical translation of memory reconsolidation research: Therapeutic methodology for transformational change by erasing implicit emotional learnings driving symptom production. International Journal of Neuropsychotherapy, 6(1), 1-92. doi: 10.12744/ijnpt.2018.0001-0092

Elshawi, R., Sakr, S., Talia, D., \& Trunfio, P. (2018). Big data systems meet machine learning challenges: Towards big data science as a service. Big Data Research, 14, December, https://doi.org/10.1016/j.bdr.2018.04.004

Fernandez, E. (November 10, 2019). Are the past and future real? The physics and philosophy of time. Forbes.com. Available at https://www.forbes.com/sites/fernandezelizabeth/2019/11/10/are-the-past-and-future-real-thephysics-and-philosophy-of-time/?sh=1fa56fca4905

Fortunato, V. C. R., Giraldi, J. D. M. E., \& De Oliveira, J. H. C. (2014). A review of studies on neuromarketing: Practical results, techniques, contributions and limitations. Journal of Management Research, 6(2), 201-220.

Gallo, C. (2011). Innovation Secrets of Steve Jobs: Insanely Different Principles for Breakthrough Success. McGraw-Hill Education: New York, NY.

Gottieb, J., \& Weinberg, A. (2019). Catch them if you can: How leaders in data and analytics have pulled ahead. McKinsey Analytics, 1-8. Available at

https://www.mckinsey.com/ /media/McKinsey/Business\%20Functions/McKinsey\%20Analytics/Our\%20Insigh ts/Catch\%20them\%20if\%20you\%20can\%20How\%20leaders\%20in\%20data\%20and\%20analytics\%20have $\% 20$ pulled\%20ahead/Catch-them-if-you-can-How-leaders-in-data-and-analytics-have-pulled-ahead.pdf

Greene, D., Hoffmann, A. L., \& Stark, L. (2019, January). Better, nicer, clearer, fairer: A critical assessment of the movement for ethical artificial intelligence and machine learning. In Proceedings of the 52nd Hawaii international conference on system sciences, pp. 2122-2131. 
Greenwood, J. (1998). The role of reflection in single and double loop learning. Journal of Advanced Nursing, 27(5), 1048-1053.

Haggard, P. (2019). The neurocognitive bases of human volition. Annual Review of Psychology, 70, 9-28.

Hashem, I.A.T., Yaqoob, I., Anuar, N.B., Mokhtar, S., Gani, A., \& Khan, S.U. (2015). The rise of "big data” on cloud computing: Review and open research issues. Information Systems, 47, 98-115. http://dx.doi.org/10.1016/j.is.2014.07.006

Iansiti, M., \& Lakhani, K.R. (2020). Competing in the Age of AI. Harvard Business Review Press: Boston, MA.

Istvan, Z. (14 May 2019). Death could soon become a curable disease. Metro.co.uk, available at https://metro.co.uk/2019/05/14/death-could-soon-become-a-curable-disease-9191393/

Jarrahi, M.H. (2018). Artificial intelligence and the future of work: Human-AI symbiosis in organizational decision making. Business Horizons, 61(4), 577-586.

Jiang, L., Stocco, A., Losey, D.M., Abernethy, J. A., Prat, C. S., \& Rao, R. P. N. (2019). BrainNet: A multi-person brain-to-brain interface for direct collaboration between brains. Scientific Reports 9, 6115. https://doi.org/10.1038/s41598-019-41895-7

Josephson, B. D. (2002). 'Beyond quantum theory: a realist psycho-biological interpretation of reality' revisited. Biosystems, 64(1-3), 43-45.

Kahneman, D. (2011). Thinking, fast and slow. Macmillan: New York, NY.

Kaplan R. S., \& Norton, D. P. (1996). Using the balanced score card as a strategic management system. Harvard Business Review, 74(1) 75-85.

Kapur, A., Sarawgi, U., Wadkins, E., Wu, M., Hollenstein, N., \& Maes, P. (2020, April). Non-invasive silent speech recognition in multiple sclerosis with dysphonia. In Machine Learning for Health Workshop, pp. 25-38. PMLR. Available at http://proceedings.mlr.press/v116/kapur20a.html

Kross, E. (2021). Chatter: The Voice in Our Head, Why It Matters, and How to Harness It. Crown Publishing Group: New York, NY.

Lance, B.J., Kerick, S.E., Ries, A.J., Oie, K.S., \& McDowell, K. (2012). Brain-computer interface technologies in the coming decades. Proceedings of the IEEE, 100(no. Special Centennial Issue), 1585-1599, May 13, 2012. doi: 10.1109/JPROC.2012.2184830 Available at https://arxiv.org/ftp/arxiv/papers/1211/1211.0886.pdf

Lau, R.R. (2003). Models of decision-making. In Sears, D.O., Huddy, L., Jervis, R., (Eds.) Oxford Handbook of Political Psychology. Oxford University Press: Oxford, UK, pp. 19-59. Available online: https://psycnet.apa.org/record/2003-88243-002

de Lavilléon, G., Lacroix, M., Rondi-Reig, L., \& Benchenane, K. (2015). Explicit memory creation during sleep demonstrates a causal role of place cells in navigation. Nature Neuroscience, 18(4), 493-495. https://doi.org/10.1038/nn.3970

Lee, M. (2019). Alphabet: The Becoming of Google. Routledge: New York, NY.

Lee, S., Hwang, C., \& Moon, M. J. (2020). Policy learning and crisis policy-making: Quadruple-loop learning and COVID-19 responses in South Korea. Policy and Society, 39(3), 363-381. https://www.tandfonline.com/doi/full/10.1080/14494035.2020.1785195

Leifer, L. J., \& Steinert, M. (2011). Dancing with ambiguity: Causality behavior, design thinking, and triple-looplearning. Information Knowledge Systems Management, 10(1-4), 151-173. 
Longo, G.O. (2002). Body and technology: Continuity or discontinuity. In Fortunati, L., Katz, J.E., Riccini, R., (Eds.) Mediating the Human Body: Communication, Technology and Fashion. Lawrence Erlbaum: Mahwah, NJ, USA, pp. 23-30.

Luoma, J. (2016). Model-based organizational decision making: A behavioral lens. European Journal of Operational Research, 249, 816-826.

Martins, N. R. B., Angelica, A., Chakravarthy, K., Svidinenko, Y., Boehm, F. J., Opris, I., Lebedev, M. A., Swan, M., Garan, S. A., Rosenfeld, J. V., Hogg, T., \& Freitas, R. A. (2019). Human brain/cloud interface. Frontiers in Neuroscience, 13. Available at https://www.frontiersin.org/articles/10.3389/fnins.2019.00112/full

McClory, S., Read, M., \& Labib, A. (2017). Conceptualising the lessons-learned process in project management: Towards a triple-loop learning framework. International Journal of Project Management, 35(7), 1322-1335.

McMichael, A. J., Woodruff, R. E., \& Hales, S. (2006). Climate change and human health: Present and future risks. The Lancet, 367(9513), 859-869.

Merali, Z. (August 17, 2020). This twist on Schrödinger's cat paradox has major implications for quantum theory. Scientific American. Available at https://www.scientificamerican.com/article/this-twist-on-schroedingers-catparadox-has-major-implications-for-quantum-theory/

Meyer, R., \& Madrigal, A. C. (March 15, 2021). Why the pandemic experts failed: We're still thinking about pandemic data in the wrong ways. The Atlantic. Available at https://www.theatlantic.com/science/archive/2021/03/americas-coronavirus-catastrophe-began-withdata/618287/

Milner, T., \& Rosenstreich, D. (2013). A review of consumer decision-making models and development of a new model for financial services. Journal of Financial Services, 18(2), 106-120.

Musk, E. (2017). Making humans a multi-planetary species. New Space, 5(2), 46-61.

Myllykoski, J. (2017). Strategic Change Emerging in Time. Dissertation at the University of Oulu Graduate School; University of Oulu. Acta Univ. Oul. G 91. 2017. Available online at http://jultika.oulu.fi/files/isbn9789526215426.pdf

Nilashi, M., Samad, S., Ahmadi, N., Ahani, A., Abumalloh, R. A., Asadi, S., ... \& Yadegaridehkordi, E. (2020). Neuromarketing: a review of research and implications for marketing. Journal of Soft Computing and Decision Support Systems, 7(2), 23-31.

Nutt, P. C., \& Wilson, D. C. (Eds.). (2010). Handbook of decision making (Vol. 6). John Wiley \& Sons: Chichester, West Sussex, UK.

Paul, M. (September 19, 2012). Your memory is like the telephone game: Each time you recall an event, your brain distorts it. Northwestern.edu. Available at https://news.northwestern.edu/stories/2012/09/your-memory-is-likethe-telephone-game

Peschl, M. F. (2007). Triple-loop learning as foundation for profound change, individual cultivation, and radical innovation: Construction processes beyond scientific and rational knowledge. Constructivist Foundations, 2(23), 136-145.

Rieger, C., \& Majchrzak, T. A. (2019). Towards the definitive evaluation framework for cross-platform app. ModelDriven Software Development. C. Rieger Dissertation WWU Munster: pp. 127-187. Available at https://d$\underline{\text { nb.info/120739100X/34\#page }=151}$

Russ, M. (2018). Introduction and a theoretical framework for knowledge management for sustainable water systems. In M. Russ (Ed.) Handbook of Knowledge Management for Sustainable Water Systems. John Wiley \& Sons, Inc.: Hoboken, NJ, pp. 1-12. Available at https://doi.org/10.1002/9781119271659.ch0 
Russ M. (2021). Knowledge management for sustainable development in the era of continuously accelerating technological revolutions: A framework and models. Sustainability, 13(6):3353.

https://doi.org/10.3390/su13063353.

Russ, M., Fineman, R., \& Jones, J.K. (2010). Conceptual theory: What do you know? in M. Russ, (Ed.) Knowledge Management Strategies for Business Development, pp. 1-22. Business Science Reference: Hershey, PA. DOI: 10.4018/978-1-60566-348-7.ch001. Draft available at https://www.uwgb.edu/UWGBCMS/media/faculty-siterussm/files/chapter_1_russ_fineman_jones_2008.pdf

Scharmer, C. O. (2009). Theory U: Learning from the Future as It Emerges. Berrett-Koehler Pub. Inc.: San Francisco, CA.

Seidl, D. (2004). Luhmann's theory of autopoietic social systems. Munich Business Research, 2, 1-28. Available at https://www.zfog.bwl.uni-muenchen.de/files/mitarbeiter/paper2004_2.pdf

Senge, P. (2006). The Fifth Discipline: The Art \& Practice of The Learning Organization. Doubleday: New York, NY.

Shahid, N., Rappon, T., \& Berta, W. (2019). Applications of artificial neural networks in health care organizational decision-making: A scoping review. PloS one, 14(2), e0212356.

Soon, C. S., Brass, M., Heinze, H. J., \& Haynes, J. D. (2008). Unconscious determinants of free decisions in the human brain. Nature Neuroscience, 11(5), 543-545.

Spatharou, A., Hieronimus, S., \& Jenkins, J. (March 10, 2020). Transforming healthcare with AI: The impact on the workforce and organizations. McKinsey \& Company. Available at https://www.mckinsey.com/industries/healthcare-systems-and-services/our-insights/transforming-healthcarewith-ai

Trakadas, P., Simoens, P., Gkonis, P., Sarakis, L., Angelopoulos, A., Ramallo-González, A. P., ... \& Karkazis, P. (2020). An artificial intelligence-based collaboration approach in industrial IoT manufacturing: Key concepts, architectural extensions and potential applications. Sensors, 20(19), 5480.

Vaishya, R., Javaid, M., Khan, I.H., \& Haleem, A. (2020). Artificial intelligence (AI) applications for COVID-19 pandemic. Diabetes \& Metabolic Syndrome, 14(4), 337-339. doi:10.1016/j.dsx.2020.04.012

White, C. (2004). Starbucks: The third place. In Strategic Management, pp. 766-772. Palgrave: London.

Wilson, C., \& Dowlatabadi, H. (2007). Models of decision making and residential energy use. Annual Review of Environment and Resources, 32, 169-203. doi:10.1146/annurev.energy.32.053006.141137

Wood, H. (2014). Human-machine interfaces expand the functionality of prosthetic limbs. Nature Reviews Neurology, 10, 671. https://doi.org/10.1038/nrneurol.2014.212

Wright, M., Robbie, K., \& Ennew, C. (1997). Serial entrepreneurs. British Journal of Management, 8(3), 251-268.

Xue, L., Yang, F., Yang, C., Chen, X., Zhang, L., Chi, Y., \& Yang, G. (2017). Identification of potential impacts of climate change and anthropogenic activities on streamflow alterations in the Tarim River Basin, China. Scientific Reports, 7(1), 1-12.

Yukalov, V. I., \& Sornette, D. (2016). Quantum probability and quantum decision-making. Philosophical Transactions Royal Society A 374, 2058. http://dx.doi.org/10.1098/rsta.2015.0100

Yuthas, K., Dillard, J. F., \& Rogers, R. K. (2004). Beyond agency and structure: Triple-loop learning. Journal of Business Ethics, 51(2), 229-243. 